\title{
Time to relapse and remission of bipolar disorder: findings from a I-year prospective study in Thailand
}

This article was published in the following Dove Press journal:

Neuropsychiatric Disease and Treatment

21 August 2013

Number of times this article has been viewed

\author{
Thawatchai Leelahanaj' \\ Ronnachai Kongsakon ${ }^{2}$ \\ Somrak Choovanichvong ${ }^{3}$ \\ Sookjaroen Tangwongchai ${ }^{4}$ \\ Suchat Paholpak ${ }^{5}$ \\ Thoranin Kongsuk ${ }^{6}$ \\ Manit Srisurapanont ${ }^{7}$
}

\section{For the Thai Bipolar \\ Registry Study Group}

'Department of Psychiatry and Neurology, Phramongkutklao Hospital, Bangkok, Thailand; ${ }^{2}$ Department of Psychiatry, Ramathibodi Hospital, Mahidol University, Bangkok, Thailand; ${ }^{3}$ Srithanya Hospital, Nonthaburi, Thailand; ${ }^{4}$ Department of Psychiatry, Chulalongkorn University, Bangkok, Thailand; ${ }^{5}$ Department of Psychiatry, Khon Kaen University, Khon Kaen, Thailand; 'Prasrimahabhodi Psychiatric Hospital, Ubon Ratchathani, Thailand; ${ }^{7}$ Department of Psychiatry, Chiang Mai University, Chiang Mai, Thailand

Correspondence: Manit Srisurapanont Department of Psychiatry, Faculty of Medicine, Chiang Mai University, I 10 Intavaroros Road, Muang,

Chiang Mai 50200, Thailand

Tel +66 53945422

Fax +66 53945426

Email manit.s@cmu.ac.th
Background and methods: This study aimed to determine time to relapse and remission of mood episodes in Thai patients with bipolar disorder (BD). The Thai Bipolar Disorder Registry was a multicenter, prospective, naturalistic, observational study conducted in Thailand. Participants were adult inpatients or outpatients with Diagnostic and Statistical Manual of Mental Disorders bipolar disorder. The diagnosis of bipolar disorder, current psychiatric comorbidity, mood relapse, and mood remission were determined by using the Mini International Neuropsychiatric Interview. Relapse and remission were assessed every 2 months.

Results: Of 424 BD participants, 404 (95.3\%) were BD I, and 258 (60.8\%) were female. At entry, 260 (61.3\%) had recovered, and 49 (11.6\%) were recovering. During 1-year followup (381.7 person-years), 92 participants $(21.7 \%)$ had 119 relapses or 0.31 (95\% confidence interval 0.25-0.35) episodes per person-year. Among 119 relapses, 58 (48.7\%), 39 (32.7\%), and $21(17.6 \%)$ of them were depressive, hypomanic, and manic episodes, respectively. Using the Kaplan-Meier method, we found that $25 \%$ of the participants relapsed in 361 days. Of the 400 participants who reached remission, 113 (28.2\%) had mood relapses. Of 173 mood events accountable for remission analysis, the median time to remission was 67.5 days ( 72.5 days for depressive episodes versus 58.0 days for manic episodes, $\log$ rank $P=0.014$ ).

Conclusions: The 1-year relapse rate in Thai patients with BD was $21.7 \%$ or 0.31 episodes per person-year. About one-fifth of recovered patients had mood relapses within 371 days. On average, a mood episode would remit in 67.5 days.

Keywords: bipolar disorder, course, outcome, relapse, remission, Thai

\section{Introduction}

The longitudinal course of bipolar disorder (BD) is characterized by a high rate of relapse and a low rate of remission. Up to $90 \%$ of $\mathrm{BD}$ patients have at least one relapse in their lifetime, with an average of 0.6 relapses per year. ${ }^{1,2}$ After recovery from a mood episode, nearly 50\% subsequently had a relapse within 2 years, despite receiving treatment at a specialty clinic for mood disorders. ${ }^{3}$ Relapse of mood episodes, delayed remission, and residual symptoms usually lead to hospitalization, increased suicide risk, and/or impede psychosocial recovery. Poor interepisodic functioning is therefore a common problem of BD patients.

Information on the clinical course of BD, including time to relapse and remission, will provide a valuable tool for planning and evaluating the health-outcome results of treatment. However, the evidence on relapse and remission obtained from randomized controlled trials is difficult to generalize to clinical practice. This problem is mainly caused by the exclusion of those at high risk of suicide and substantial 
medical or psychiatric comorbidity, particularly substance abuse, from a randomized controlled trial. In a long-term, prospective, natural study in 146 BD I patients, the duration of a major depressive episode was longer than that of a manic episode, highlighting that a depressive episode was associated with a worse general course of illness. ${ }^{4}$ Some findings suggest that patients with mixed episodes take a longer time to recover and have poorer outcomes than those with pure manic or hypomanic episodes. ${ }^{5,6}$ In a 4-year, prospective, natural study in 123 BD patients with psychotic features who were first hospitalized, $24.3 \%$ and $35.9 \%$ of them had mood relapses within 6 and 12 months, respectively. ${ }^{7}$ The median times to relapse were 26 weeks for depression, 48 weeks for mania, and 56 weeks for mixed episodes. In this latter study, the median time to remission was approximately 16 weeks.

While patterns of BD may be different between Asian and Caucasian patients, ${ }^{8,9}$ little is known about the outcomes of BD in Asian patients. The 1-year relapse rate of $55 \%$ in Taiwanese BD patients was relatively higher than the findings obtained from Caucasian BD patients $(35.9 \%){ }^{7}$ In this study, we aimed to determine time to relapse and remission of mood episodes in Thai patients with $\mathrm{BD}$, who were naturally followed up for 1 year in secondary and tertiary care settings.

\section{Materials and methods}

The Thai Bipolar Disorder Registry was a 1-year, prospective, natural study conducted in 24 general, mental, and university hospitals across Thailand. Of these, nine and 15 were academic and nonacademic settings, respectively. All study sites provided both outpatient and inpatient services for mentally ill patients. The study was carried out between February 2009 and January 2011. The primary objective of this registry was to characterize the illness course of BD in Thai patients. The study did not involve any clinical management of participants. The study protocol was approved by the institutional review board or the ethics committee of each study site. Prior to participation, each patient gave written informed consent after the study details had been fully explained.

\section{Participants}

Participants were inpatient or outpatients with BD I or II aged 18 years or more. We excluded those participating in other investigational studies and those with travel difficulties. Apart from the reimbursement of transportation cost, participants received no financial benefit from their participation.

\section{Assessment}

We assessed all participants at entry (visit 1) and every 2 months ( \pm 1 month) for a period of 12 months (visits 2-7). More visits could be added if a participant had a relapse or severe condition. Baseline data included demographic data, history of BD, physical comorbidity, and psychiatric treatment. The diagnosis of BD, current psychiatric comorbidity, relapse, and remission were determined using the Mini International Neuropsychiatric Interview (MINI), version 5. ${ }^{10}$ The MINI is a structured diagnostic psychiatric interview for the Diagnostic and Statistical Manual of Mental Disorders (DSM)-IV and the International Classification of Diseases ICD (version 10) that had been translated into Thai, and its validity has been tested against board-certified psychiatrists' interviews. In a clinical sample of 177 patients with various mental disorders, including 30 patients each with depression or mania/hypomania, the sensitivity and specificity of the MINI-Thai modules were 0.98 and 0.94 for major depressive episodes, and 0.89 and 0.94 for (hypo)manic episodes, respectively. ${ }^{11}$ Other MINI modules applied for determining current psychiatric comorbidity were those for panic disorder, agoraphobia, social phobia (social anxiety disorder), obsessive-compulsive disorder, alcohol abuse and dependence, nonalcohol psychoactive substance-use disorders, and generalized anxiety disorder. The raters of all sites received the MINI training provided by the MINI-Thai developers. These developers had been trained and granted permission to translate the MINI and validate the MINI-Thai.

The severity of symptoms and syndromes was measured by using the Young Mania Rating Scale (YMRS) - Thai version, ${ }^{12}$ the Montgomery-Åsberg Depression Rating Scale (MADRS) - Thai version, ${ }^{13}$ and the Clinical Global Impressions of Bipolar Disorder - Severity (CGI-BP-S). ${ }^{14}$ All measures used in visit 1 were also applied in visit 7. Only the MINI, major depression and (hypo)mania modules were applied at each visit between visits 2 and 6. All measures were administered by trained psychiatrists.

Based on the aforementioned measures and DSM-IV diagnostic criteria, certified psychiatrists interviewed the participants to differentiate BD I and II. In this study, syndromal remission was defined as a stage in which a participant did not meet the diagnosis of MINI, major depressive, or (hypo)manic episode for a consecutive period of 8 weeks. For a syndromal relapse, it was the development of a mood episode, determined by using the MINI, major depressive or (hypo)manic episode, in a participant who once had reached the remission stage. In the original MINI, the time frames used for assessing mood episodes were 2 weeks and current 
(2-3 weeks) for major depressive and (hypo)manic episodes, respectively. For those who had an admission due to a major depressive/(hypo)manic episode or a report of moderate/ severe mood change, the time frames were extended to cover that period. Meeting of both major depressive and (hypo) manic episodes in the same visit was considered as a mixed episode.

\section{Statistical analysis}

The demographic data at baseline, including history of $\mathrm{BD}$, psychiatric comorbidity and treatments, and baseline bipolar status (ie, MINI diagnosis and comorbidity, YMRS score, MADRS score, CGI-BP-S score) were summarized by counts and percentages. The statistical significance for a test was set at $P<0.05$.

The data of those fulfilling the syndromal remission definition at entry or any time point were included in the relapse analysis. Based on the aforementioned definitions of relapse and remission, time to relapse was the duration between the time point where a previous mood episode remitted and the first time a relapse was found. In the survival analysis, an end point other than the relapse of a mood episode was considered as censored. The survival curves were drawn according to the Kaplan-Meier method. The proportion (\%) of end-point relapses was calculated based on incidencedensity rate. Comparison of event-free survival between groups was done by using the two-sided log-rank test.

Only mood events meeting DSM-IV major depressive or (hypo)manic episodes were included in the remission analyses. Time to remission was the duration between the time when a mood relapse was found and the time when the mood syndrome of that particular relapse remitted. The survival analysis was conducted by using the methods applied for the survival analysis of mood relapses.

\section{Results}

\section{Sample characteristics and clinical status}

Of 424 BD participants, 404 (95.3\%) were BD I, and $258(60.8 \%)$ were female. Mean ( \pm standard deviation) ages at entry and onset were $42.7( \pm 12.3)$ and $31.8( \pm 11.9)$ years, respectively. The first mood episode of most patients was manic/hypomanic $(n=274,64.8 \%)$. Current psychiatric comorbidity was found in 83 participants (19.6\%) in which all comorbid disorders were anxiety and substance-use disorders. Other demographic and clinical characteristics are presented in Table 1.

At entry, 260 participants $(61.3 \%)$ and 49 participants $(11.6 \%)$ had recovered and were recovering, respectively
Table I Demographic characteristics of 424 patients with bipolar disorder

\begin{tabular}{|c|c|}
\hline Demographic characteristics & $\mathbf{N}(\%)$ \\
\hline Male & 166 (39.2\%) \\
\hline \multicolumn{2}{|l|}{ Bipolar disorder subtype } \\
\hline Bipolar I disorder & $404(95.3 \%)$ \\
\hline Bipolar II disorder & $20(4.7 \%)$ \\
\hline History of rapid cycling in the previous year & $23(5.4 \%)$ \\
\hline \multicolumn{2}{|l|}{ Polarity at first episode } \\
\hline Depressive episode & $109(25.8 \%)$ \\
\hline Manic/hypomanic episode & $274(64.8 \%)$ \\
\hline Mixed & $28(6.6 \%)$ \\
\hline Unknown & $12(2.8 \%)$ \\
\hline \multicolumn{2}{|l|}{ Psychiatric disorder in first degree relative } \\
\hline Bipolar disorder & $55(13.0 \%)$ \\
\hline Major depressive disorder & $25(5.9 \%)$ \\
\hline Schizophrenia & $19(4.5 \%)$ \\
\hline Anxiety disorders & $14(3.3 \%)$ \\
\hline Substance use disorders & $4(1.0 \%)$ \\
\hline Participants with one comorbidity or more & $83(19.6 \%)$ \\
\hline Generalized anxiety disorder & $18(5.3 \%)$ \\
\hline Obsessive compulsive disorder & $15(4.4 \%)$ \\
\hline Panic disorder & $14(4.1 \%)$ \\
\hline Agoraphobia & $13(3.8 \%)$ \\
\hline Social phobia & $9(2.6 \%)$ \\
\hline Alcohol use disorder & $31(9.1 \%)$ \\
\hline \multirow[t]{2}{*}{ Non-alcohol use disorder } & II (3.2\%) \\
\hline & Mean ( $\pm S D)$ \\
\hline Age at entry (years) & $42.7( \pm 12.3)$ \\
\hline Age at onset of illness (years) & $31.8( \pm 11.9)$ \\
\hline Age at first diagnosis (years) & $36.4( \pm 12.1)$ \\
\hline \multicolumn{2}{|l|}{ Duration to undiagnosed bipolar disorder (years) } \\
\hline Depressive episode & $4.8( \pm 6.7)$ \\
\hline Manic/hypomanic episode & $4.0( \pm 6.9)$ \\
\hline Mixed & $\mathrm{I} .3( \pm 4.1)$ \\
\hline Age at first hospitalization (years) & $34.5( \pm \mathrm{I} I .7)$ \\
\hline Number of mood episodes prior to entry & $5.0( \pm 5.3)$ \\
\hline Number of hospitalizations prior to entry & $2.9( \pm 2.6)$ \\
\hline
\end{tabular}

Abbreviation: SD, standard deviation.

(see Table 2). The remaining 115 participants (27.1\%) were still symptomatic. Of the symptomatic patients, 31 participants $(7.3 \%)$ each were depressed and manic (see Table 2). In concordance with the mild symptoms of this sample, the means ( \pm standard deviation) of the YMRS and the MADRS scores were $2.9( \pm 2.6)$ and 3.8 $( \pm 5.6)$, respectively.

Of the 424 participants at enrollment, follow-up was completed in 383 participants $(90.3 \%)$. Reasons for dropouts $(\mathrm{n}=41)$ were consent withdrawal $(\mathrm{n}=10)$, loss to follow-up $(n=25)$, death $(n=4)$, referral to another hospital $(n=1)$, and missing data $(n=1)$. The medications received at entry and 12-month visit were similar; antipsychotics and mood stabilizers were more common than other medications (see Table 3). 
Table 2 Clinical status of the participants at enrollment $(n=424)$

\begin{tabular}{|c|c|}
\hline Clinical status & $\mathbf{N}(\%)$ \\
\hline Recovered $^{\mathrm{a}}$ & $260(61.3 \%)$ \\
\hline Recovering ${ }^{\mathrm{b}}$ & 49 (II.6\%) \\
\hline Symptomatic & $115(27.1 \%)$ \\
\hline Continued symptomatic ${ }^{c}$ & 17 (4.0\%) \\
\hline Depressed $^{d}$ & $31(7.3 \%)$ \\
\hline Manic $^{d}$ & $31(7.3 \%)$ \\
\hline Hypomanic $^{d}$ & $13(3.1 \%)$ \\
\hline Mixed $^{d}$ & $20(4.7 \%)$ \\
\hline \multirow[t]{2}{*}{ Rougheninge } & $3(0.7 \%)$ \\
\hline & Mean ( \pm SD) \\
\hline YMRS (0-60) & $3.8( \pm 5.6)$ \\
\hline MADRS $(0-60)$ & $4.8( \pm 6.6)$ \\
\hline \multicolumn{2}{|l|}{ CGI-BP-S } \\
\hline Mania $(I-7)$ & $1.7( \pm \mid .2)$ \\
\hline Depression (I-7) & $\mathrm{I} .5( \pm \mathrm{I} . \mathrm{I})$ \\
\hline Overall bipolar illness (I-7) & $1.8( \pm 1.2)$ \\
\hline
\end{tabular}

Notes: a Having two symptoms or fewer for 8 consecutive weeks or more; bhaving two symptoms or fewer for less than 8 weeks; chaving three symptoms or more, not fulfilling the DSM-IV diagnostic criteria for a mood episode, and having no recovered status during 8 weeks prior to entry; ${ }^{d}$ clinical status corresponding to DSM-IV diagnostic criteria for a mood episode; ehaving three symptoms or more, not fulfilling the DSM-IV diagnostic criteria for a mood epiosode, and having a recovered status during 8 weeks prior to entry.

Abbreviations: YMRS, Young Mania Rating Scale; MADRS, Montgomery Asberg Depression Rating Scale; CGI-BP-S, Clinical Global Impression - BP version, severity of illness; SD, standard deviation; DSM-IV, Diagnostic and Statistical Manual of Mental Disorders - 4th Edition.

\section{Relapses during I-year follow-up}

For the 1-year follow-up of this cohort $(n=424)$, we observed all the 381.7 person-years and found 119 relapses of mood episodes in 92 patients $(21.7 \%)$. The incidence of mood relapse was 0.31 episodes per person-year (95\% confidence interval [CI] 0.25-0.35), which was equivalent to one episode for every 3.2 person-years (95\% CI 2.5-4.0). Among the 92 patients with relapses, 15 of them $(16.3 \%)$ had two relapses each, and another six participants (6.5\%) three relapses each. Among 119 relapses of mood episodes, 58 of them (48.7\%)

Table 3 Medications received at entry and 12-month visit

\begin{tabular}{|c|c|c|}
\hline Medications & $\begin{array}{l}\text { At entry } \\
(N=424)\end{array}$ & $\begin{array}{l}\text { I } 2 \text { months } \\
(\mathrm{N}=383)\end{array}$ \\
\hline Antipsychotics & $313(73.8 \%)$ & $261(68.1 \%)$ \\
\hline Typical antipsychotics $^{\mathrm{a}}$ & $174(41.0 \%)$ & $137(35.8 \%)$ \\
\hline Atypical antipsychotics ${ }^{\mathrm{a}}$ & $129(30.4 \%)$ & II 3 (29.5\%) \\
\hline Combined use ${ }^{a}$ & $10(2.4 \%)$ & II (2.9\%) \\
\hline Mood stabilizers (anticonvulsant) & $282(66.5 \%)$ & $263(68.7 \%)$ \\
\hline Benzodiazepines & $208(49.1 \%)$ & $176(46.0 \%)$ \\
\hline Lithium & 178 (42.0\%) & 155 (40.5\%) \\
\hline Anticholinergic agents & $166(39.2 \%)$ & $129(33.7 \%)$ \\
\hline Antidepressants & $81(19.1 \%)$ & $62(16.2 \%)$ \\
\hline Others ${ }^{\mathrm{b}}$ & $16(3.8 \%)$ & $19(5.0 \%)$ \\
\hline
\end{tabular}

Notes: aSubgroups are presented in a mutually exclusive manner; bropanolol and zolpidem. were depressive, 39 (32.7\%) were hypomanic, and 21 (17.6\%) were manic. We found no relapse of mixed mood.

\section{Time to relapse}

A total of 400 participants who fulfilled the definition of remission status were included in the relapse analysis. Of these, 86 patients $(21.5 \%)$ had mood relapses within a total observable period of 371 days (the last 86th patient had a mood relapse at 371 days). Using the Kaplan-Meier method, we found that $30.8 \%$ of the participants had mood relapses in 371 days, which corresponded to $12.5 \%$ in 6 months or $28.2 \%$ in 1 year (see Figure 1). Ten percent of them relapsed in 134.5 days (95\% CI 64.6-209.0), 20\% in 300.8 days (95\% CI 237.3-348.2), and 25\% in 361 days (95\% CI $300.3->371$ days). Because the relapses occurred in less than $50 \%$ of the participants, the median time for relapse (days needed for $50 \%$ of the participants to have relapses) could not be calculated.

We further compared the medians of time to relapse among three subgroups categorized by the last mood episodes and types of mood at the relapse episode. The results showed no difference in medians of time to relapse among patients with a last mood episode of depression $(n=28$, median 162 days, interquartile range (IQR) 58.5-268.5) and those with a last mood episode of mania $(n=31$, median 196.5 days, IQR 63.5-293.0; $\log$ rank $P=0.509)$. There was a trend of time to hypomanic relapse being shorter than that to manic relapse, whereas the time to depressive relapse was in between ( $\log$ rank $P=0.083)$ (see Figure 2).

\section{Time to remission}

There were 173 mood events accountable for the remission analysis. For the Kaplan-Meier plot, the median time to remission of a mood episode was 67.5 days (95\% CI 62.1-74.1), with an IQR of 52.0-122.0 days (Figure 3). For the subgroup analysis, time to remission of a depressive episode was significantly longer than that of a manic episode (median 72.5 days, IQR 57.0-119.0; 58.0 days, IQR 54.0-105.0; $\log$ rank $P=0.014$; Figure 4). Other subgroup comparisons revealed no significant difference.

\section{Discussion}

In this prospective naturalistic follow-up study of 424 Thai patients with $\mathrm{BD}$, the 1 -year relapse rate was $21.7 \%$, or 0.31 episodes per person-year. Almost half the relapses were major depressive episodes. About one-fifth of the recovered patients had mood relapses within 371 days. Possibly due to the small sample of participants with mood relapses, we 


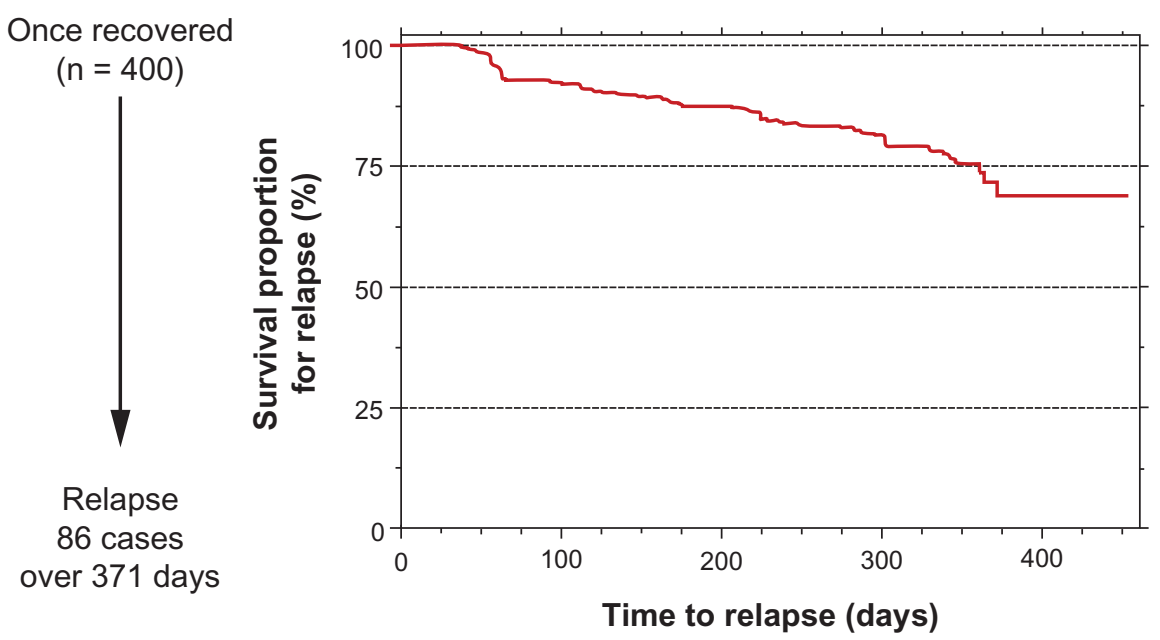

\begin{tabular}{|l|c|c|c|c|c|}
\hline Day & 0 & 100 & 200 & 300 & 350 \\
\hline \# of subjects at risk & 400 & 359 & 326 & 238 & 66 \\
\hline Duration & - & 100 days & 6 months & 9 months & 1 year \\
\hline$\%$ of relapse & - & 7.8 & 12.5 & 16.6 & 28.2 \\
\hline
\end{tabular}

Figure I Kaplan-Meier plot for the relapse-survival analysis.

found no impact of the last mood episodes and types of mood at the relapse episode, on time to relapse. On average, a mood episode would remit in 67.5 days, and the time to remission of a depressive episode was longer than that of a manic one (72.5 versus 58.0 days).
The 1-year relapse rate of $21.7 \%$ found in this study was lower than those of $35 \%-55 \%$ found in previous studies. ${ }^{7,15,16}$ Differences in sample, clinical characteristics, and methodology of these studies may have played a role in the lower relapse rate of this study. First, while the residual

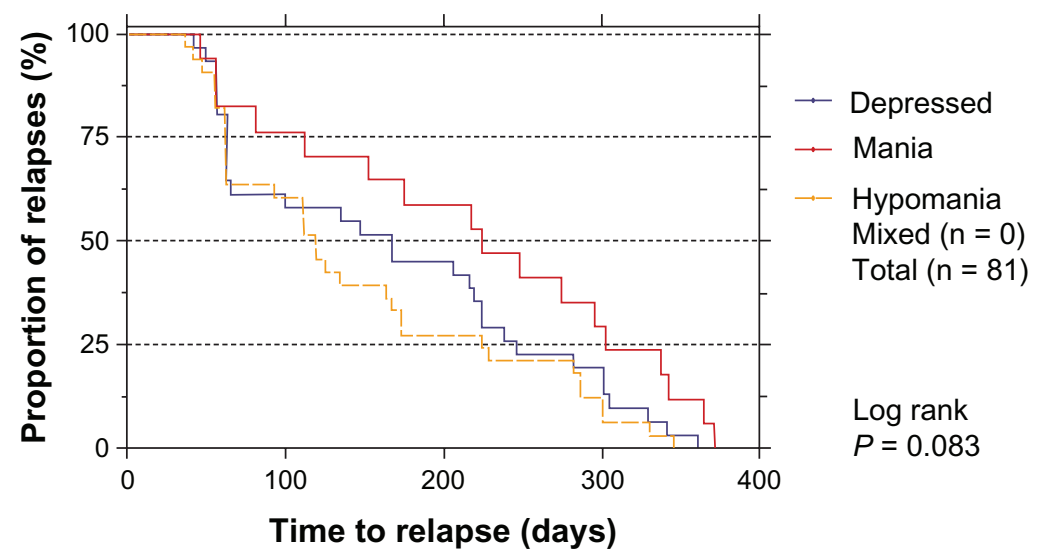

\begin{tabular}{|l|c|c|}
\hline Mood at the episode & $\mathrm{n}$ & Median time to relapse $(95 \% \mathrm{Cl}$, day) \\
\hline Depressive & 31 & $167.0(61.3-220.5)$ \\
\hline Manic & 17 & $224.0(76.0-296.3)$ \\
\hline Hypomanic & 33 & $119.0(62.2-166.0)$ \\
\hline
\end{tabular}

Figure 2 Kaplan-Meier analysis of time to relapse categorized by types of mood at the relapse episode. Abbreviation: $\mathrm{Cl}$, confidence interval. 


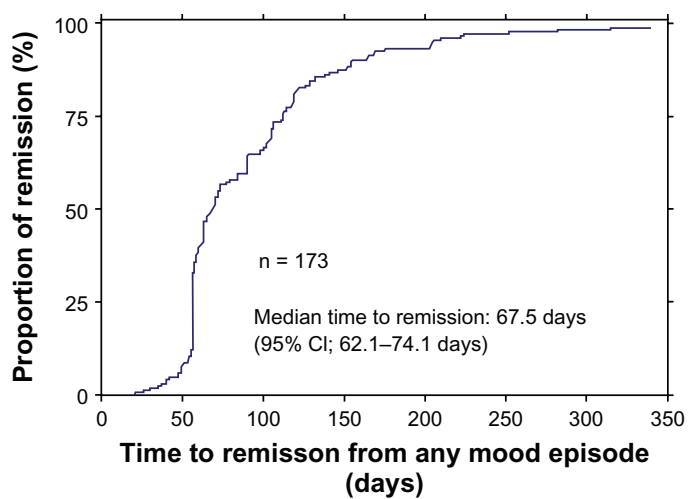

Figure 3 Kaplan-Meier analysis of time to remission for the 173 participants who had any type of mood relapse.

Abbreviation: $\mathrm{Cl}$, confidence interval.

depressive or manic symptoms at recovery are predictors of mood relapse, ${ }^{3}$ most of the present sample were outpatients in recovered $(61.3 \%)$ or recovering $(11.6 \%)$ stages, who had no residual symptoms of the mood. Second, other good predictors found in this sample included later onset of illness (mean 36.4 years) and a small proportion of BD patients with history of rapid cycling (5.4\%). ${ }^{17}$ Third, Thai bipolar patients may have a different illness phenotype compared with Taiwanese and Western BD patients. Fourth, this study included many nonacademic sites, which might have patients with a less severe illness course. Last, different from all previous studies, the present one used the MINI to determine a mood episode.

While the median time to relapse of this study was longer than that of a previous study ( 8.9 months or 267 days), ${ }^{18}$ its median time to remission (67.5 days) was shorter than previous findings (16 weeks or 112 days). ${ }^{7}$ Because less than $50 \%$ of this sample had relapses in 1 year, the median time to relapse could not be calculated. Only the finding that $25 \%$ of the sample relapsed in 361 days could be found. It was possible that the aforementioned favorable clinical characteristics might have contributed to the longer time to relapse and the shorter time to remission found in this study.

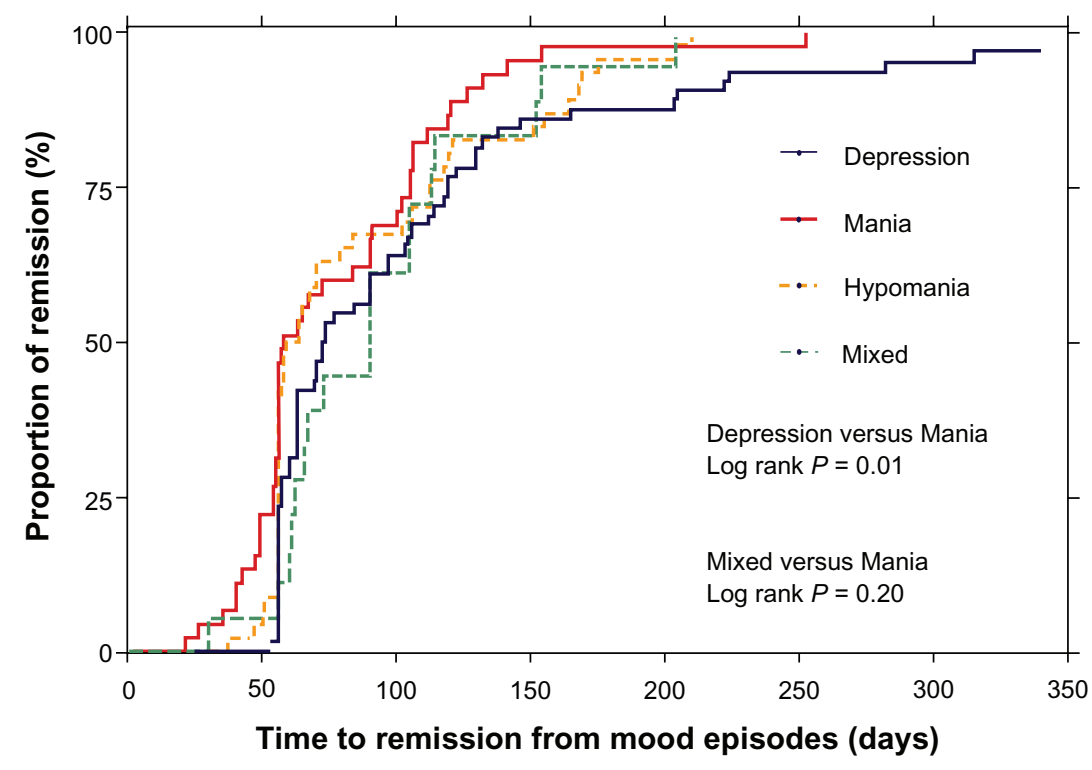

\begin{tabular}{|l|c|c|}
\hline & $\mathrm{n}$ & $\begin{array}{c}\text { Median time to remission } \\
(95 \% \text { confidence interval, days })\end{array}$ \\
\hline Depression & 62 & $72.5(61.0-89.6)$ \\
\hline Mania & 45 & $58.0(54.9-84.2)$ \\
\hline Hypomania & 46 & $61.0(55.6-69.6)$ \\
\hline Mixed & 18 & $90.0(<60.0-99.4)$ \\
\hline
\end{tabular}

Figure 4 Kaplan-Meier analysis of time to remission categorized by types of relapsing mood. 
The finding that time to remission of a depressive episode was longer than that of a manic episode was similar to previous findings, in which Coryell and colleagues reported a mean duration of 11 weeks for depression compared with 6 weeks for mania. ${ }^{19}$

The low comorbidity rate of mental disorders $(19.6 \%)$ found in this study might have been caused by several factors. Due to the nature of MINI diagnosis, only current psychiatric comorbidity could be determined in this study. The present findings therefore might not be comparable to those of previous studies, which assessed lifetime comorbidity. Little awareness of and low resources providing for mental disorders may also have contributed to the lower rate of psychiatric comorbidity. However, the common comorbidity of anxiety and substance-use disorders found in this study was in line with most of the previous findings..$^{20,21}$

In this study, only $5 \%$ of the enrolled patients were diagnosed with BD II. Several factors may be attributed to the low prevalence of BD II in Thai patients, eg, underdiagnosis in clinical practices, patients' insight into their hypomanic experiences, and inherent features of the clinical course of the illness. ${ }^{22-24}$ However, a previous study also found that the prevalence of BD II in Asian patients was lower than that in Caucasian patients. ${ }^{9}$

There were some limitations of this study. First, the follow-up period was too short to determine some outcomes, eg, median time to relapse. Second, the 2-month interval between visits might be too long to identify an occurrence of brief mood episode and have contributed to the low relapse rate found in this study. Third, partly due to the lower relapse rate, the subgroups of patients with different types of mood at the relapse episode were too small to detect the impact of relapsing mood on time to remission. Last, because the present participants had recovered or were recovering at baseline, they tended to have favorable clinical characteristics. Generalizing the present findings to severe BD patients, eg, hospitalized patients and those with psychotic features, should therefore be done with caution.

In conclusion, the 1-year relapse rate in Thai $\mathrm{BD}$ patients was $21.7 \%$ or 0.31 episodes per person-year. Almost half the relapses were major depressive episodes. About one-fifth of recovered patients had mood relapses within 371 days. On average, a mood episode would remit in 67.5 days, and time to remission of a depressive episode was longer than that of a manic one. Further studies with longer study duration and shorter interval of assessment are warranted.

\section{Acknowledgments}

This study was supported by an unrestricted research grant from Sanofi-Aventis (Thailand) Ltd. However, Sanofi-Aventis (Thailand) had no role in the study design, the analysis plan, or the preparation of this manuscript. Statistical analysis was provided by Ms Taweeporn Natesamroeng, a statistician of Sanofi-Aventis (Thailand) Ltd. We thank Dr Panadda Klamsum of Sanofi-Aventis (Thailand) Ltd for her administrative support. The Thai Bipolar Registry Study Group are Buddhachinnaraj Hospital: R Kanokvut, P Lengdee, U Wilekha; Chachoengsao Hospital: W Pratoomsri; Galya Rajanagarindra Institute: W Thomkapanich; Institute of Aviation Medicine: P Onsiri; Khon Kaen Rajanagarindra Psychiatric Hospital: K Kittiwattanagul; King Chulalongkorn Memorial Hospital: P Lueboonthavatchai, C Roomruangwong, S Tangwongchai; Maharaj Nakorn Chiang Mai Hospital: M Srisurapanont, S Sutthijit; Phrae Hospital: S Tongprasert; Phramongkutklao Hospital: T Leelahanaj; Phrapokklao Hospital: S Sarakul; Prasrimahabhodhi Psychiatric Hospital: S Janthong, T Kongsuk; Rajavithi Hospital: P Thomyangkoon; Ramathibodi Hospital: P Ittasakul, R Kongsakon; Ratchaburi Hospital: S Limsiroratana, W Pattanakumjorn; Rayong Hospital: P Pattaranuthaporn; Siriraj Hospital: S Bussaratid; Somdet Chaopraya Institute of Psychiatry: W Chanakul, P Losatiankij; Srinagarind Hospital: S Paholpak; Srithanya Hospital: S Choovanichvong; Suansaranrom Psychiatric Hospital: S Joowong; Surin Hospital: K Surapongpiwattana, T Surapongpiwattana; Thammasat University Hospital: L Kosulwit; Udonthani Hospital: W Wongsuriyadech; Vachira Phuket Hospital: T Sumpatanarax.

\section{Disclosure}

The following authors have received consultancy fees, research grants and/or honoraria from industry, but none related to this work: Dr Thawatchai Leelahanaj from AstraZeneca, Eisai, Eli Lilly, GlaxoSmithkline, Janssen, Pfizer, Sanofi-Aventis, Servier, and Thai Otsuka; Dr Sookjaroen Tangwongchai from AstraZeneca, Eisai, GlaxoSmithKline, Janssen-Cilag, Lundbeck, Novartis, Pfizer, Sanofi-Aventis, Servier, and Thai-Osuka; Dr Suchat Paholpak from AstraZeneca, Janssen, Novartis, Pfizer, Sanofi-Aventis, and Thai Otsuka; Dr Srisurapanont from AstraZeneca, GlaxoSmithKline, Pfizer, Janssen, Johnson \& Johnson, Lundbeck, Sanofi-Aventis, Servier, and Thai Otsuka. Drs Ronnachai Kongsakol, Somrak Choovanichvong, and Thoranin Kongsuk report no conflict of interest in this work. 


\section{References}

1. Goodwin FK, Jamison KR. Manic-Depressive Illness. New York: Oxford University Press; 1990.

2. Winokur G, Coryell W, Keller M, Endicott J, Akiskal H. A prospective follow-up of patients with bipolar and primary unipolar affective disorder. Arch Gen Psychiatry. 1993;50(6):457-465.

3. Perlis RH, Miyahara S, Marangell LB, et al. Long-term implications of early onset in bipolar disorder: data from the first 1000 participants in the systematic treatment enhancement program for bipolar disorder (STEP-BD). Biol Psychiatry. 2004;55(9):875-881.

4. Judd LL, Akiskal HS, Schettler PJ, et al. The long-term natural history of the weekly symptomatic status of bipolar I disorder. Arch Gen Psychiatry. 2002;59(6):530-537.

5. Dilsaver SC, Swann AC, Shoaib AM, Bowers TC, Halle MT. Depressive mania associated with nonresponse to antimanic agents. Am J Psychiatry. 1993;150(10):1548-1551.

6. Swann AC. [Prediction of treatment response in acute mania: controlled clinical trials with divalproex.] Encephale. 2001;27(3):277-279. French.

7. Bromet EJ, Finch SJ, Carlson GA, et al. Time to remission and relapse after the first hospital admission in severe bipolar disorder. Soc Psychiatry Psychiatr Epidemiol. 2005;40(2):106-113.

8. Strakowski SM, Tsai SY, Delbello MP, et al. Outcome following a first manic episode: cross-national US and Taiwan comparison. Bipolar Disord. 2007;9(8):820-827.

9. Hwang SHJ, Childers ME, Wang PW, et al. Higher prevalence of bipolar I disorder among Asian and Latino compared to Caucasian patients receiving treatment. Asia Pac Psychiatry. 2010;2(3):156-165.

10. Sheehan DV, Lecrubier Y, Sheehan KH, et al. The Mini-International Neuropsychiatric Interview (M.I.N.I.): the development and validation of a structured diagnostic psychiatric interview for DSM-IV and ICD10. J Clin Psychiatry. 1998;59 Suppl 20:22-33.

11. Udomratn P, Kittirattanapaiboon P. The Mini-International Neuropsychiatric Interview (Thai Version). Bangkok: Graphic Hut; 2004.

12. Kongsakon R, Bhatanaprabhabhan D. Validity and reliability of the Young Mania Rating Scale: Thai version. J Med Assoc Thai. 2005;88(11): 1598-1604.

13. Kongsakon R, Zartrugpak S, Rotjananirunkit A, Buranapichet U. The reliability and validity of the Thai version of Montgomery Asberg Depression Rating Scale (MADRS). J Psychiatr Assoc Thai. 2003;48: 211-219.
14. Spearing MK, Post RM, Leverich GS, Brandt D, Nolen W. Modification of the Clinical Global Impressions (CGI) Scale for use in bipolar illness (BP): the CGI-BP. Psychiatry Res. 1997;73(3):159-171.

15. Otto MW, Simon NM, Wisniewski SR, et al. Prospective 12-month course of bipolar disorder in out-patients with and without comorbid anxiety disorders. Br J Psychiatry. 2006;189:20-25.

16. Tang $\mathrm{CH}$, Hsieh MH, Hung ST, Lee IH, Lin YJ, Yang YK. One-year post-hospital medical costs and relapse rates of bipolar disorder patients in Taiwan: a population-based study. Bipolar Disord. 2010;12(8): 859-865.

17. Suppes T, Dennehy EB, Gibbons EW. The longitudinal course of bipolar disorder. J Clin Psychiatry. 2000;61 Suppl 9:23-30.

18. Mantere O, Suominen K, Valtonen HM, et al. Differences in outcome of DSM-IV bipolar I and II disorders. Bipolar Disord. 2008;10(3): $413-425$.

19. Coryell W, Endicott J, Keller M. Outcome of patients with chronic affective disorder: a five-year follow-up. Am J Psychiatry. 1990;147(12): $1627-1633$

20. Grant BF, Stinson FS, Hasin DS, et al. Prevalence, correlates, and comorbidity of bipolar I disorder and axis I and II disorders: results from the National Epidemiologic Survey on Alcohol and Related Conditions. J Clin Psychiatry. 2005;66(10):1205-1215.

21. Ostacher MJ, Perlis RH, Nierenberg AA, et al. Impact of substance use disorders on recovery from episodes of depression in bipolar disorder patients: prospective data from the Systematic Treatment Enhancement Program for Bipolar Disorder (STEP-BD). Am J Psychiatry. 2010;167(3): 289-297.

22. Cassano GB, Dell'Osso L, Frank E, et al. The bipolar spectrum: a clinical reality in search of diagnostic criteria and an assessment methodology. J Affect Disord. 1999;54(3):319-328.

23. Hadjipavlou G, Mok H, Yatham LN. Bipolar II disorder: an overview of recent developments. Can J Psychiatry. 2004;49(12):802-812.

24. Benazzi F. Bipolar II disorder: epidemiology, diagnosis and management. CNS Drugs. 2007;21(9):727-740.
Neuropsychiatric Disease and Treatment

\section{Publish your work in this journal}

Neuropsychiatric Disease and Treatment is an international, peerreviewed journal of clinical therapeutics and pharmacology focusing on concise rapid reporting of clinical or pre-clinical studies on a range of neuropsychiatric and neurological disorders. This journal is indexed on PubMed Central, the 'PsycINFO' database and CAS.

\section{Dovepress}

The manuscript management system is completely online and includes a very quick and fair peer-review system, which is all easy to use. Visit http://www.dovepress.com/testimonials.php to read real quotes from published authors. 